\title{
Livin/BIRC7 gene expression as a possible diagnostic biomarker for endometrial hyperplasia and carcinoma
}

\author{
Basma K. Elmekkawy ${ }^{1}$, Rasha M. S. Shoaib ${ }^{1}$, Amal K. Seleem², Dalia Shaalan² and Entsar A. Saad ${ }^{1 *}$ (D)
}

\begin{abstract}
Background: Livin/BIRC7 is a member of the inhibitors of apoptosis proteins family which are implicated in development of cancer through the inhibition of apoptosis process. This case-control study was intended to investigate livin/BIRC7 gene expression in endometrial hyperplasia and carcinoma and its correlation to some oxidative stress markers in addition to its possible diagnostic performance.
\end{abstract}

Methods: This study included 90 participants [30 endometrial hyperplasia patients, 30 endometrial carcinoma patients, and 30 healthy controls]. Livin/BIRC7 gene expression was analyzed using quantitative reverse transcriptasepolymerase chain reaction (RT-PCR). Serum catalase activity was assessed by enzyme-linked immunosorbent assay (ELISA) and malondialdehyde level was measured by the colorimetric method.

Results: $L i v i n / B I R C 7$ gene expression was significantly $(p<0.001)$ higher in endometrial carcinoma from patients with endometrial hyperplasia when compared to controls. A positive correlation was found between livin/BIRC7 expression and serum catalase activity and malondialdehyde level in endometrial hyperplasia and carcinoma. The detection of livin/BIRC7 in endometrial carcinoma has excellent sensitivity and specificity.

Conclusions: Livin/BIRC7 was overexpressed in endometrial carcinoma with excellent power to differentiate endometrial carcinoma from endometrial hyperplasia or healthy subjects, suggesting that it might be a useful molecular marker for endometrial carcinoma diagnosis.

Keywords: Endometrial hyperplasia, Endometrial carcinoma, Livin, BIRC7, Gene expression

\section{Background}

Endometrial hyperplasia is an abnormal proliferation of glands and stroma of the endometrium highlighted with the existence of cytologic and tissue architectural amendments [1]. Endometrial hyperplasia, if not cured, has the tendency to progress into endometrial carcinoma [2]. During carcinogenesis and as a central step for cancer development, malignant cells inactivate apoptosis. They neglect apoptosis signals, which regularly direct cells to stop reproduction or to start cell apoptosis to dispose of the abnormal cancerous cells. This

\footnotetext{
* Correspondence: entsarsaad@gmail.com; entsarsaad@du.edu.eg

${ }^{1}$ Chemistry Department, Faculty of Science, Damietta University, Mobark

street, New-Damietta, Damietta 34517, Egypt

Full list of author information is available at the end of the article
}

inactivation of apoptotic signals may be a significant subscriber to therapy resistance in several neoplasms [3].

Among the most common cancers worldwide, the endometrial cancer is the 15th and it is the 6th among women cancers with more than 380,000 new diagnosed cases and about 90,000 deaths in 2018. The numbers are rising yearly, with the highest incidence in Canada and the USA [4]. However, in low-income and middleincome countries, the fatality/incidence rate is still high [5]. Extended unlimited estrogen exposure, age, obesity, diabetes, race, nulliparity, infertility, early age of menarche, family history, late age of menopause, and tamoxifen drug are the important threats for the development of endometrial cancer [6]. The percent of 5-year survival in endometrial cancer, without spread to another place, 
is between 74 and 91 [7]. A great number of the cases are diagnosed at the early stage (I or II) and showed a better prognosis and the possibility of no recurrence after surgery and adjuvant radiotherapy. Nevertheless, from 10 to $15 \%$ recurs. Between 80 and $90 \%$ of recurrences occur within 3 years [8]. Localized recurrences, which mostly appear in the vaginal vault, are more likely to develop in the early-stage patients treated with surgery solely. More distant recurrences are more probable to happen in patients initially cured by multimodality treatment [https://www.cancertherapyadvisor.com/ home/decision-support-in-medicine/obstetrics-andgynecology/endometrial-chemotherapy-treatment-forrecurrence/]. Many unanswered research questions remain concerning controlling this disease ranging from treatment toxicity, diagnostic procedures to adjuvant therapy [4]. There are no definite lab analyses for the diagnosis of endometrial cancer. The recommended ways are either transvaginal ultrasonography or endometrial biopsy. Therefore, precise diagnosis requires an endometrial tissue sample [9]. Consequently, there is a great responsibility from researchers to seek new biomarkers, which can serve as predictors and/or diagnostics for endometrial carcinoma.

Baculoviral IAP repeat-containing 7 (BIRC7), called livin and livin inhibitor-of-apoptosis as well, is one of the family members of the inhibitor of apoptosis protein (IAP) and was acknowledged to play a role in the inhibition of cell death prompted by apoptosis and adjustment of cell proliferation and cell cycle [10]. The livin/ BIRC7 protein is composed of 298 amino acid residues long with a molecular weight of about $32798 \mathrm{Da}$, enclosing three PDB structures, seven beta-strands, six turns, and nine helix domains [Data source: Uniprot database (Q96CA5)]. BIRC7 contains a single domain of Baculovirus IAP-Repeat (BIR) comprising approximately 70 amino acids and a zinc-binding RING-domain. BIRC7BIR is globular in structure stabilized by four $\alpha$-helices and an anti-parallel sheet of three filaments, in addition to residues that give the hydrophobic nucleus. Additionally, the BIRC7-RING domain is typically distinct by seven cysteines and one histidine which able to coordinate two zinc atoms in its carboxy-terminus (atlasgeneticsoncology.org). The BIR domain is required for inhibitory activity and reacts with caspases or with APAF1 which together with cytochrome $\mathrm{C}$ mediates caspase 9 activation, while the zinc-binding RING-domain sometimes rises antiapoptotic activity but does not inhibit apoptosis alone [11].

The human BIRC7 is encoded by BIRC7 (OMIM\#: 605737) gene that positioned on chromosome 20q13.33 and spanned nearly 4613 bases. The BIRC7 gene consists of seven exons with six introns [12]. Based on the genomic structure of the livin/BIRC7 gene, it has consisted of three splice variants [BIRC7-201, BIRC7-202, BIRC7203]. The protein-protein interaction networks implicated that livin/BIRC7 protein has vital functions in the apoptotic process, regulation of catalytic activity, enzyme inhibitor activity, JNK cascade, and signal transduction [Data source: STRING database, version 11.0]. The gene-gene interaction networks indicated that the livin/ $B I R C 7$ gene has crucial functions in the execution phase of apoptosis, endopeptidase inhibitor activity, negative regulation of hydrolase activity, and apoptotic DNA fragmentation [Data source: GeneMANIA database]. The subcellular localizations of the livin/BIRC7 protein indicated that it is detected with abundance in the nucleus, cytoplasm, and Golgi apparatus [Data source: Cellular compartment database].

In general, as most IAPs, BIRC7 expression was not noticeable in normal differentiated adult tissues, except placenta, spleen, lymph nodes, and developing embryonic tissues [13]. On the other hand, BIRC7 overexpression has been reported in several cancer types, in which it was associated with malignancy and chemoresistance as in adrenocortical tumors [14], prostate cancer [15], papillary thyroid carcinoma [16], bladder cancer [17], colorectal cancer [18], renal carcinoma [19], hepatocellular carcinoma [20], lung cancer [21], and acute lymphoblastic leukemia [22].

No data were identified concerning the diagnostic or prognostic impacts of livin/BIRC7 gene expression in endometrial hyperplasia and/or endometrial carcinoma. Thus, our team was motivated to explore the livin/ BIRC7 gene expression in both endometrial hyperplasia and carcinoma, in relation to some oxidative stress markers, and its diagnostic performance to help in developing better treatment strategies.

\section{Methods \\ Study population}

This preliminary case-control study included 90 women divided into 3 groups: 30 women with endometrial hyperplasia (group I), 30 women with endometrial carcinoma (group II), and 30 healthy controls (group III). They were diagnosed and recruited between November 2017 and December 2019 from the Obstetrics and Gynecology Clinic of Mansoura University Hospital, Mansoura, Egypt. Only endometrial hyperplasia cases diagnosed with simple endometrial hyperplasia without atypia were included. They were with a mean age of 49.73 years. Only endometrial carcinoma cases diagnosed with endometrial carcinoma of stage I were included. They were with a mean age of 52.16 years. Patients were at pre-menopause and post-menopause stages. Healthy controls were randomly selected of matched sex and mean age (women with a mean age of 51.83 years). Women with endometrial hyperplasia of 
other types, with endometrial carcinoma of higher stages, with chronic non-specific endometritis and fibroid were excluded. Clinical characteristics of the study groups are listed in Table 1. Written informed consents were gotten from all study contributors with a declaration of data privacy.

\section{Samples collection}

Five milliliters of peripheral venous blood was received from all study contributors using sterile venipuncture and plastic disposable syringes. Each sample was portioned into two tubes; $3 \mathrm{~mL}$ blood without anticoagulant and centrifuged for $15 \mathrm{~min}$ at $5000 \mathrm{rpm}$ to get serum for assessment of estrogen level, catalase activity, and malondialdehyde level. Two milliliters of blood with ethylene diamine tetraacetic acid was used for RNA extraction.

\section{Estimation of estrogen hormone level}

The estrogen hormone level was determined by the quantitative competitive enzyme-linked immunosorbent assay (ELISA) kit (Sigma-Aldrich, SE120049, USA) following the kit instructions.

\section{Estimation of malondialdehyde (MDA) level}

The serum MDA level was measured by the colorimetric method kit (Elabscience, E-BC-K025-M, USA) following the manufacturer instructions.

\section{Estimation of catalase enzyme activity}

The serum catalase activity was assessed according to the manufacturer instructions of the colorimetric method kit (Abcam, ab83464, USA).

\section{Livin/BIRC7 gene expression by RT-PCR}

Total RNA isolation was done using a Tri-FastTM reagent kit (PeqLab Biotechnologie GmbH, Germany) according to the Chomczynski method [23]. Reverse transcriptase-polymerase chain reaction (RT-PCR) was done using the QIAGEN One-step RT-PCR kit (QIAG EN, Valencia, USA) according to McPherson and Moller method [24]. Each sample was analyzed in duplicate. Quantitative RT-PCR is then performed as follows: Livin/BIRC7 gene-specific primers (Biolegio BV, Nijmegen, Netherlands): Forward: (5'-d [ATG GGC TCT GAG GAG TTG CGT C]-3). Reverse: (5'-d [CAT AGC AGA AGA AGC CC TCA CCT TG]-3'). Internal control (GAPDH) gene-specific primers: Forward: $\left(5^{\prime}-\mathrm{d}\right.$ [CGG AGT CAA CGG ATT TGG TCG TAT]-3'). Reverse: (5'-d [AGC CTT CTC CAT GGT GGT GAA GAC]-3'). The reaction mixture was performed in a final volume of $50 \mu \mathrm{L}$ containing $40 \mu \mathrm{L}$ of master mix $(20 \mu \mathrm{L}$ RNase free water, $10 \mu \mathrm{L}$ of $5 \times$ RT-PCR buffer, $2 \mu \mathrm{L}$ dNTP mix which is $10 \mathrm{mM}$ of each dNTP, $3 \mu \mathrm{L}$ sense primer, $3 \mu \mathrm{L}$ antisense primer, and $2 \mu \mathrm{L}$ RT-PCR enzyme mix) and $10 \mu \mathrm{L}$ of each template RNA. Reactions were performed using TECHNE TC-312 thermal Cycler PCR. Amplification steps involved $15 \mathrm{~min}$ of initial PCR activation at $95{ }^{\circ} \mathrm{C}$, then 35 cycles of 1 min of denaturation at $94{ }^{\circ} \mathrm{C}, 1 \mathrm{~min}$ of annealing at $58{ }^{\circ} \mathrm{C}$, and $1 \mathrm{~min}$ of extension at $72{ }^{\circ} \mathrm{C}$. A final extension was done at $72^{\circ}$ for $10 \mathrm{~min}$. PCR products were electrophoresed on $2 \%$ agarose gel and visualized on the UV transilluminator. The obtained bands were digitally photographed under fixed conditions (the light, the distance, and the zoom). Photos analysis was carried out via using the scion image

Table 1 Demographic and biochemical data of the studied groups

\begin{tabular}{|c|c|c|c|}
\hline & Endometrial hyperplasia $(n=30)$ & Endometrial carcinoma $(n=30)$ & Control $(n=30)$ \\
\hline Age (years) & $49.73 \pm 1.07$ & $52.16 \pm 1.08$ & $51.83 \pm 1.17$ \\
\hline$p$ value & $0.12^{*}$ & $0.79^{\$}$ & $0.19 !$ \\
\hline Bodyweight (kg) & $93.47 \pm 2.71$ & $77.67 \pm 2.12$ & $84.70 \pm 2.58$ \\
\hline$p$ value & $<0.001^{*}$ & $0.06^{\$}$ & $0.02 !$ \\
\hline Estrogen $(\mathrm{pg} / \mathrm{mL})$ & $30.87 \pm 2.34$ & $26.80 \pm 1.75$ & $29.67 \pm 2.06$ \\
\hline$p$ value & $0.17^{*}$ & $0.33^{\$}$ & $0.68 !$ \\
\hline Catalase $(\mathrm{mU} / \mathrm{mL})$ & $0.18 \pm 0.01$ & $0.21 \pm 0.02$ & $0.17 \pm 0.01$ \\
\hline$p$ value & $0.093^{*}$ & $0.027^{\$}$ & $0.57^{!}$ \\
\hline Malondialdehyde $(\mu \mathrm{mol} / \mathrm{L})$ & $6.51 \pm 0.28$ & $9.09 \pm 0.36$ & $3.17 \pm 0.21$ \\
\hline$p$ value & $<0.001^{*}$ & $<0.001^{\$}$ & $<0.001 !$ \\
\hline
\end{tabular}

$M \pm S E$ : mean \pm standard error; pairwise comparison between each 2 groups was done using post hoc test

*Comparison between endometrial hyperplasia and endometrial carcinoma

\$Comparison between endometrial carcinoma and control

'Comparison between control and endometrial hyperplasia 
release Alpha 4.0.3.2 software for windows ${ }^{\bullet}$ which accomplishes detection of bands and conversion to peaks. Areas under each peak were calculated in square pixels and used in quantification. Livin/BIRC7 gene expression was determined by calculating the ratio between the square pixel value of the Livin/BIRC7 gene in relation to the GAPDH gene.

\section{Statistical analysis}

The data processing, manipulation, and organization were presented utilizing the IBM SPSS statistics program, version 26.0 (Thousand Oaks, CA, USA). The normal distribution of the study data was assessed using the Kolmogorov-Smirnov test. The continuous variables were processed as mean \pm standard error $(\mathrm{SE})$ using the one-way ANOVA test. Pairwise comparison between every 2 groups was done using post hoc test (Dunn's test) for multiple comparisons test. Correlations between the clinical variables were analyzed using the Pearson correlation test. The receiver operating characteristic (ROC) curve was plotted to determine the cut-off point. $p \leq 0.05$ was considered significant. The boxplot was carried out by the $\mathrm{R}$ programming Language (version 4.0.3) with RStudio open source (version 1.4.1103).

\section{Results}

Demographic and biochemical data of the studied groups The demographic and biochemical data of all studied groups are presented in Table 1. This study involved 90 women divided into three groups: group 1-30 women with endometrial hyperplasia with a mean age \pm standard error (SE) was $49.73 \pm 1.07$ years; group 2-30 women with endometrial carcinoma with a mean age \pm SE was $52.16 \pm 1.08$ years, and group III -30 healthy controls with a mean age \pm SE was $51.83 \pm 1.30$ years. The groups were well balanced in terms of age and estrogen level. The mean weight was higher in patients with endometrial hyperplasia compared to endometrial carcinoma patients and controls $(p<0.001$ and $p=0.02$; respectively). Catalase activities of endometrial carcinoma cases were higher than those of the control cases ( $p$ $=0.027$ ). Additionally, the MDA levels were significantly elevated among endometrial carcinoma in comparison to endometrial hyperplasia patients and controls ( $p$ value $<0.001$ ) (Table 1).

\section{Livin/BIRC7 expression in endometrial hyperplasia, endometrial carcinoma, and healthy controls}

The expression of Livin/BIRC7 as shown in Table 2 was elevated among patients with endometrial hyperplasia and endometrial carcinoma in comparison to controls $(p$ $<0.001)$. Besides, the livin/BIRC7 expression was higher in patients with endometrial carcinoma $(1.59 \pm 0.11)$
Table 2 Livin/BIRC7 expression level in the studied groups

\begin{tabular}{lll}
\hline Studied groups & Livin/BIRC7 expression & $\boldsymbol{p}$ value \\
\hline Endometrial hyperplasia $(n=30)$ & $0.68 \pm 0.06$ & $<\mathbf{0 . 0 0 1 *}$ \\
Endometrial carcinoma $(n=30)$ & $1.59 \pm 0.11$ & $<\mathbf{0 . 0 0 1}$ \\
Control $(n=30)$ & $0.17 \pm 0.03$ & $<\mathbf{0 . 0 0 1}$
\end{tabular}

$M \pm S E:$ mean \pm standard error

${ }^{*}$ Comparison between endometrial hyperplasia and endometrial carcinoma

\$Comparison between endometrial carcinoma and control

'Comparison between control and endometrial hyperplasia

than that in endometrial hyperplasia patients $(0.68 \pm$ 0.06) $(p<0.001)$.

\section{Bio-statistical correlations between the studied parameters}

Livin/BIRC7 expression and the bodyweight of studied populations was negatively correlated $(r=-0.24)$. On the contrary, significant positive correlations were observed between the livin/BIRC7 expression, catalase ( $r=$ $0.22)$ and MDA $(r=0.66)$. Moreover, the activity of catalase correlated positively with MDA level $(r=0.23)$ as demonstrated in Table 3 . No significant correlations were found between estrogen level and any of the studied parameters.

\section{Diagnostic performance}

The ROC curve analysis was applied to assess the power of livin/BIRC7 expression, catalase activity, and MDA levels in discriminating between endometrial carcinoma, hyperplasia, and normal endometria. As regard to predicting endometrial hyperplasia (Table 4), livin/BIRC7 expression and MDA were significant $(p<0.001)$, AUC $=0.95$ and 0.97 respectively compared to 0.53 for catalase $(p=0.66)$. The MDA had better sensitivity $(100 \%)$ whereas livin/BIRC7 expression had better specificity (90\%). Similarly, livin/BIRC7 expression and MDA were significant $(p<0.001)$, AUC $=0.998$ and 0.991 respectively compared to 0.613 for catalase $(p=0.13)$ in predicting endometrial carcinoma (Table 5). The livin/ BIRC7 expression had better sensitivity (100\%) while MDA had better specificity (100\%). In differentiating endometrial carcinoma from endometrial hyperplasia (Table 6), livin/BIRC7 expression was the most powerful with $\mathrm{AUC}=0.94$ compared to 0.87 and 0.59 for MDA and catalase respectively. The livin/BIRC7 expression had better sensitivity (93.3\%).

\section{Discussion}

Globally, endometrial cancer is the 6th utmost common cancer in females and the utmost common malignancy of the female genital area [25]. Predictive, diagnostic, and prognostic biomarkers were identified for several other cancers [26-28]. The present study was the 
Table 3 Pearson's correlation analysis among all the studied parameters

\begin{tabular}{|c|c|c|c|c|c|c|c|c|c|c|}
\hline \multirow[t]{2}{*}{ Parameters } & \multicolumn{2}{|c|}{ Livin/BIRC7 expression } & \multicolumn{2}{|l|}{ Age } & \multicolumn{2}{|c|}{ Bodyweight } & \multicolumn{2}{|c|}{ Estrogen } & \multicolumn{2}{|c|}{ Catalase } \\
\hline & $r$ & $p$ & $r$ & $p$ & $r$ & $p$ & $r$ & $p$ & $r$ & $p$ \\
\hline \multicolumn{11}{|c|}{ Livin/BIRC7 expression } \\
\hline Age & 0.06 & 0.56 & & & & & & & & \\
\hline Bodyweight & -0.24 & $0.03^{*}$ & -0.003 & 0.98 & & & & & & \\
\hline Estrogen & -0.07 & 0.49 & -0.003 & 0.98 & 0.06 & 0.58 & & & & \\
\hline Catalase & 0.22 & $0.04^{*}$ & -0.04 & 0.74 & -0.06 & 0.56 & -0.14 & 0.18 & & \\
\hline Malondialdehyde & 0.66 & $<0.001^{*}$ & 0.04 & 0.68 & -0.19 & 0.07 & -0.09 & 0.35 & 0.23 & $0.03^{*}$ \\
\hline
\end{tabular}

$r$ : parametric correlation (Pearson $r$ )

*: $p \leq 0.05$ is significant

pioneer to investigate the role of livin/BIRC7 gene expression in endometrial hyperplasia and carcinoma.

A vital mechanism involved in tumorigenesis is the inhibition of apoptosis [29]. There have been accumulated evidence that overexpression of BIRC7 in cancers has been connected to chemo- and radio-resistance, relapse, and poor survival [30]. The reported data that in normal tissues Livin/BIRC7 is ordinarily not detected [31], but overexpressed in malignant tissues was confirmed by our results which demonstrated that livin/BIRC7 gene is over-expressed in our patient groups 1 and 2 . The expression was significantly higher in carcinoma than hyperplasia suggesting that the more the severity of the disease is the greater the level of expression. The results also recommended livin/BIRC7 gene over-expression as a true risk factor for endometrial carcinoma. Several mechanisms have been established by which livin/BIRC7 over-expression enhances malignancies [32]. Among these, the antiapoptotic activity of livin/BIRC7 is mediated through inhibition of caspase-3, -7 , and -9 , as well as by its E3 ubiquitin-ligase-like activity which stimulates Smac/DIABLO degradation which plays a crucial role in the activation of caspases [33]. It was also found that there were two similar splicings of livin, livin- $\alpha$, and

Table 4 Diagnostic performance of livin/BIRC7 expression, catalase, and malondialdehyde (MDA) for prediction of endometrial hyperplasia

\begin{tabular}{llll}
\hline & Livin/BIRC7 expression & Catalase & MDA \\
\hline Cutoff & $>0.30$ & $>0.14$ & $>4.12$ \\
AUC & 0.950 & 0.530 & 0.970 \\
Sensitivity \% & $96.7 \%$ & $70.0 \%$ & $100 \%$ \\
Specificity \% & $90.0 \%$ & $36.7 \%$ & $83.3 \%$ \\
Accuracy & $86 \%$ & $7 \%$ & $83 \%$ \\
PPV \% & $90.6 \%$ & $52.5 \%$ & $85.7 \%$ \\
NPV \% & $96.4 \%$ & $55.0 \%$ & $100.0 \%$ \\
95\% Cl & $0.87-0.99$ & $0.39-0.66$ & $0.89-0.99$ \\
$\boldsymbol{p}$ value & $<\mathbf{0 . 0 0 1}$ & 0.66 & $<\mathbf{0 . 0 0 1}$ \\
\hline A & . &
\end{tabular}

$A U C$ : area under the curve, $P P V:$ positive predictive value, NPV: negative predictive value, $\mathrm{Cl}$ : confidence interval livin- $\beta$ that could be distinguished by the presence of 18 amino acids positioned at the interval of the BIR and RING domains in the $\alpha$-isoform. Although they are similar in structure, the different isoforms show different anti-apoptotic features [34] and consequently differ in their tumorigenic manner.

According to our findings, the bodyweight was significantly higher in patients with endometrial hyperplasia confirming high bodyweight as a risk factor for endometrial hyperplasia. However, in endometrial carcinoma, bodyweight showed a tendency to decline. This was ascertained further in our work by the significant negative correlation found between bodyweight and the livin/ BIRC7 gene expression. Bodyweight decline in carcinoma may be due to the predominance of the catabolic status at the expense of the anabolic status and the change to anaerobic metabolism due to oxygen lack leading to energy waste via the Cori cycle. As the livin/ $B I R C 7$ gene expression was significantly upregulated and was further higher in endometrial carcinoma patients than in endometrial hyperplasia cases. Similar behavior was observed for MDA as well; it was significantly elevated in endometrial hyperplasia and recorded further elevation associated with endometrial carcinoma

Table 5 Diagnostic performance of Livin/BIRC7 expression, catalase, and malondialdehyde (MDA) for prediction of endometrial carcinoma

\begin{tabular}{llll}
\hline & Livin/BIRC7 expression & Catalase & MDA \\
\hline Cutoff & $>0.60$ & $>0.22$ & $>5.21$ \\
AUC & 0.998 & 0.613 & 0.991 \\
Sensitivity \% & $100 \%$ & $36.7 \%$ & $96.7 \%$ \\
Specificity \% & $96.7 \%$ & $93.3 \%$ & $100 \%$ \\
Accuracy & $97 \%$ & $30 \%$ & $97 \%$ \\
PPV \% & $96.8 \%$ & $84.6 \%$ & $100 \%$ \\
NPV \% & $100 \%$ & $59.6 \%$ & $96.8 \%$ \\
95\% Cl & $0.94-1.00$ & $0.48-0.74$ & $0.92-1.00$ \\
$\boldsymbol{p}$ value & $<\mathbf{0 . 0 0 1}$ & 0.13 & $<\mathbf{0 . 0 0 1}$ \\
\hline
\end{tabular}

AUC: area under the curve, $P P V$ : positive predictive value, $N P V$ : negative predictive value, $\mathrm{Cl}$ : confidence interval 
Table 6 Diagnostic performance of Livin/BIRC7 expression, catalase, and malondialdehyde (MDA) for differentiation between endometrial carcinoma and endometrial hyperplasia

\begin{tabular}{llll}
\hline & Livin/BIRC7 expression & Catalase & MDA \\
\hline Cutoff & $>0.90$ & $>0.22$ & $>7.30$ \\
AUC & 0.940 & 0.590 & 0.870 \\
Sensitivity \% & $93.3 \%$ & $36.7 \%$ & $90.0 \%$ \\
Specificity \% & $86.7 \%$ & $86.7 \%$ & $83.3 \%$ \\
Accuracy & $80 \%$ & $23 \%$ & $73 \%$ \\
PPV \% & $87.5 \%$ & $73.3 \%$ & $84.4 \%$ \\
NPV \% & $92.9 \%$ & $57.8 \%$ & $89.3 \%$ \\
95\% Cl & $0.84-0.98$ & $0.45-0.71$ & $0.76-0.94$ \\
$\boldsymbol{p}$ value & $<\mathbf{0 . 0 0 1}$ & 0.24 & $<\mathbf{0 . 0 0 1}$ \\
\hline
\end{tabular}

$A U C$ : area under the curve, $P P V:$ positive predictive value, $N P V$ : negative predictive value, $\mathrm{Cl}$ : confidence interval

confirming the great association in lipid peroxidation with disease development and progression. High levels of reactive species have anti-apoptotic effects in tumor cells that appear as a result of redox-sensitive transcription factors activation [35] resulting in triggering cellular proliferation, cell migration, and invasion, all of which participate in carcinogenesis [36]. Surprisingly, in the current study, the antioxidant enzyme catalase was significantly highly activated in endometrial carcinoma cases compared to controls while it showed no difference between endometrial hyperplasia cases and controls in its activity. A possible explanation could be that in response to acute oxidative stress of endometrial hyperplasia, antioxidants including catalase may be expended to prevent the oxidative-dependent damage. This is in the same line with Ota et al. [37]. Nevertheless, the elevation in catalase activity in endometrial carcinoma may be one of the adaptive mechanisms exerted by the host body against excessive produced reactive species by the tumor cells. As the prolonged oxidative stress raises the production of reactive species and assumed to encourage antioxidants more release. Interestingly, this may be confirmed in light of the observed significant positive correlation between catalase activity and each of MDA and livin/BIRC7 gene expression. Therefore, our findings in the current study clearly propose that livin/BIRC7 over-expression and oxidative stress status can be affected by/and could be associated with the endometrial disease severity, chronicity, and progression. It has been reported that endometrial hyperplasia and carcinoma were associated with increased lipid peroxidation and altered antioxidant enzymes activities [38] and it was suggested [39] that lipid peroxidation elevation appears to be a consequence of the disease rather than its etiology.

In the current study, using ROC curve analysis, we found that livin/BIRC7 expression and MDA level but not the catalase could be used as additional dependable parameters in the diagnosis of the suspected cases with endometrial carcinoma and endometrial hyperplasia. Both livin/BIRC7 and MDA are excellent to distinguish endometrial hyperplasia cases from control subjects. However, MDA is better regarding AUC value (0.97 with accuracy of $83 \%$ vs. 0.95 with accuracy of $86 \%$ for livin). Also, they are excellent for differentiation of endometrial carcinoma cases from controls; however, livin/BIRC7 is more powerful than MDA regarding AUC value (0.998 vs. 0.991 ) with the same accuracy (97\%) for the two. Regarding differentiation of endometrial carcinoma from endometrial hyperplasia, the performance of both still great but livin/BIRC7 is superior regarding AUC value and accuracy (0.94 with accuracy of $80 \%$ for livin/BIRC7 vs. 0.87 with accuracy of $73 \%$ for MDA).

Some limitations were raised upon the establishment of the present work that being a single institutional study with a small sample size which might affect sensitivity of the investigated gene expression as a predictive and prognostic biomarker. Moreover, apoptotic markers in endometrial carcinoma should be studied in correlation with livin/BIRC7 gene expression.

\section{Conclusions}

In conclusion, the current study demonstrated that livin/BIRC7 and lipid peroxidation were over-expressed/ elevated in endometrial carcinoma compared to endometrial hyperplasia. We may suggest livin/BIRC7 expression in endometrial hyperplasia as a marker with a good diagnostic accuracy (area under ROC curve, 0.950), sensitivity $(96.7 \%)$, and specificity $(90.0 \%)$. While in endometrium carcinoma, we detected gene expression of high sensitivity and specificity, $100 \%$ and $96.7 \%$ respectively. Therefore, our findings provided evidence that the detection of livin/BIRC7 may be used as a reliable diagnostic biomolecular technique for endometrial carcinoma.

\section{Abbreviations}

RT-PCR: Reverse transcriptase-polymerase chain reaction; ELISA: Enzymelinked immunosorbent assay; BIRC7: Baculoviral IAP repeat-containing 7; IAP: Inhibitor of apoptosis protein; BIR: Baculovirus IAP-repeat;

MDA: Malondialdehyde; ROC curve: Receiver operating characteristic curve; SE: Standard error; AUC: Area under the curve

\section{Acknowledgements}

Authors thank Dr. Mohamed Ibrahem Eid, Ass. Professor of Obstet and Gyne, Department of Obstetrics and Gynecology, Mansoura University, Mansoura, Egypt, and everyone who helped them to accomplish this work.

\section{Authors' contributions}

BKE performed the practical work, collected data, analyzed, reviewed literature, and interpreted the results. RMSS designated and performed the analysis, writing the paper in its first form, review, and edited the paper draft AKS designed the study, collected the study participants, collected the data, interpreted the results, and supervised the work. DS performed the practical work and interpretation of the results. EAS designed the study, analyzed data, reviewed literature, reviewed, re-wrote, and re-edited the paper, prepared the final form of the manuscript, and supervised the project. All 
authors read and approved the final version of the manuscript submitted for publication.

\section{Funding}

This research did not receive any specific grant from funding agencies in the public, commercial, or not-for-profit sectors.

\section{Availability of data and materials}

Data is not available due to [ethical/legal/commercial] restrictions: Due to the nature of this research, participants of this study did not agree for their data to be shared publicly, so supporting data is not available.

\section{Declarations}

\section{Ethics approval and consent to participate}

The study was approved by the Institutional Review Board of Faculty of Medicine, Mansoura University, Egypt (Code number: R.21.02.1209). Written informed consents were gotten from all study contributors with a declaration of data privacy.

\section{Consent for publication}

Not applicable.

\section{Competing interests}

The authors declare that they have no competing interests.

\section{Author details}

${ }^{1}$ Chemistry Department, Faculty of Science, Damietta University, Mobark street, New-Damietta, Damietta 34517, Egypt. ²Department of Medical Biochemistry and Molecular Biology, Faculty of Medicine, Mansoura University, Mansoura, Egypt.

\section{Received: 19 April 2021 Accepted: 10 September 2021}

Published online: 26 September 2021

\section{References}

1. McCluggage WG (2006) My approach to the interpretation of endometrial biopsies and curettings. J Clin Pathol 59(8):801-812. https://doi.org/10.1136/ jcp.2005.029702

2. Rungruang B, Olawaiye $A B$ (2012) Comprehensive surgical staging for endometrial cancer. Rev Obstet Gynecol 5(1):28-34

3. Brown JM, Attardi LD (2005) The role of apoptosis in cancer development and treatment response. Nat Rev Cancer 5(3):231-237. https://doi.org/10.103 $8 /$ nrc1560

4. Brüggmann D, Ouassou K, Klingelhöfer D, Bohlmann MK, Jaque J, Groneberg DA (2020) Endometrial cancer: mapping the global landscape of research. J Transl Med 18(1):386. https://doi.org/10.1186/s12967-020-02554-y

5. Gu B, Shang X, Yan M, Li X, Wang W, Wang Q, Zhang C (2021) Variations in incidence and mortality rates of endometrial cancer at the global, regional, and national levels, 1990-2019. Gynecol Oncol 161(2):573-580. https://doi. org/10.1016/j.ygyno.2021.01.036

6. La Vecchia C, Franceschi S, Decarli A, Gallus G, Tognoni G (1984) Risk factors for endometrial cancer at different ages. J Natl Cancer Inst 73(3):667-67

7. Morice P, Leary A, Creutzberg C, Abu-Rustum N, Darai E (2016) Endometrial cancer. Lancet 387(10023):1094-1108. https://doi.org/10.1016/S0140-6736(1 5)00130-0

8. Sohaib SA, Houghton SL, Meroni R, Rockall AG, Blake P, Reznek RH (2007) Recurrent endometrial cancer: patterns of recurrent disease and assessment of prognosis. Clin Radiol 62(1):28-36. https://doi.org/10.1016/j.crad.2006.06. 015

9. Braun MM, Overbeek-Wager EA, Grumbo RJ (2016) Diagnosis and management of endometrial cancer. Am Fam Physician 93(6):468-474

10. Dasgupta A, Alvarado CS, Xu Z, Findley HW (2010) Expression and functional role of inhibitor-of-apoptosis protein livin (BIRC7) in neuroblastoma. Biochem Biophys Res Commun 400(1):53-59. https://doi. org/10.1016/j.bbrc.2010.08.001

11. Byers NM, Vandergaast RL, Friesen PD (2016) Baculovirus inhibitor-ofapoptosis Op-IAP3 blocks apoptosis by interaction with and stabilization of a host insect cellular IAP. J Virol 90(1):533-544. https://doi.org/10.1128/JVI. 02320-15
12. Badr EA, El Sayed IE, Assar MF, Ali SA, Ibrahim NS (2019) A pilot study of Livin gene and Yes-associated protein 1 expression in hepatocellular carcinoma patients. Heliyon. 5(11):e02798. https://doi.org/10.1016/j.heliyon.2 019.e02798

13. Augello C, Caruso L, Maggioni M, Donadon M, Montorsi M, Santambrogio R, Torzilli G, Vaira V, Pellegrini C, Roncalli M, Coggi G, Bosari S (2009) Inhibitors of apoptosis proteins (IAPs) expression and their prognostic significance in hepatocellular carcinoma. BMC Cancer 9(1):125-134. https://doi.org/10.11 86/1471-2407-9-125

14. Altieri B, Sbiera S, Della Casa S, Weigand I, Wild V, Steinhauer S, Fadda G, Kocot A, Bekteshi M, Mambretti EM, Rosenwald A, Pontecorvi A, Fassnacht M, Ronchi CL (2017) Livin/BIRC7 expression as malignancy marker in adrenocortical tumors. Oncotarget 8(6):9323-9338

15. Yang $Y$, Sun $P, X u$ W, Xia W (2018) High BIRC7 expression might be an independent prognostic indicator of poor recurrence-free survival in patients with prostate cancer. Technol Cancer Res Treat 17. https://doi.org/ https://doi.org/10.1177/1533033818809694, 153303381880969.

16. Liu K, Yu Q, Li H, Xie C, Wu Y, Ma D, Sheng P, Dai W, Jiang H (2020) BIRC7 promotes epithelial-mesenchymal transition and metastasis in papillary thyroid carcinoma through restraining autophagy. Am J Cancer Res 10(1): 78-94

17. Gazzaniga P, Gradilone A, Giuliani L, Gandini O, Silvestri I, Nofroni I, Saccani G, Frati L, Aglianò AM (2003) Expression and prognostic significance of LIVIN, SURVIVIN and other apoptosis-related genes in the progression of superficial bladder cancer. Ann Oncol 14(1):85-90. https://doi.org/10.1093/a nnonc/mdg002

18. Myung DS, Park YL, Chung CY, Park HC, Kim JS, Cho SB, Lee WS, Lee KH, Lee JH, Joo YE (2013) Expression of Livin in colorectal cancer and its relationship to tumor cell behavior and prognosis. PLoS One 8(9):e73262. https://doi.org/10.1371/journal.pone.0073262

19. Durinck S, Stawiski EW, Pavía-Jiménez A, Modrusan Z, Kapur P, Jaiswal BS, Zhang N, Toffessi-Tcheuyap V, Nguyen TT, Pahuja KB, Chen YJ, Saleem S, Chaudhuri S, Heldens S, Jackson M, Peña-Llopis S, Guillory J, Toy K, Ha C, Harris CJ, Holloman E, Hill HM, Stinson J, Rivers CS, Janakiraman V, Wang W, Kinch LN, Grishin NV, Haverty PM, Chow B, Gehring JS, Reeder J, Pau G, Wu TD, Margulis V, Lotan Y, Sagalowsky A, Pedrosa I, de Sauvage FJ, Brugarolas J, Seshagiri S (2015) Spectrum of diverse genomic alterations define nonclear cell renal carcinoma subtypes. Nat Genet 47(1):13-21. https://doi.org/1 $0.1038 /$ ng.3146

20. Cho SB, Lee WS, Park YL, Kim N, Oh HH, Kim MY, Oak CY, Chung CY, Park HC, Kim JS, Myung DS, Kim SH, Lee KH, Choi SK, Joo YE (2015) Livin is associated with the invasive and oncogenic phenotypes of human hepatocellular carcinoma cells. Hepatol Res 45(4):448-457. https://doi.org/1 0.1111/hepr.12374

21. Hariu H, Hirohashi $Y$, Torigoe $T$, Asanuma H, Hariu M, Tamura $Y$, Aketa $K$ Nabeta C, Nakanishi K, Kamiguchi K, Mano Y, Kitamura H, Kobayashi J, Tsukahara T, Shijubo N, Sato N (2005) Aberrant expression and potency as a cancer immunotherapy target of inhibitor of apoptosis protein family, Livin/ ML-IAP in lung cancer. Clin Cancer Res 11(3):1000-1009

22. Choi J, Hwang YK, Sung KW, Lee SH, Yoo KH, Jung HL, Koo HH, Kim HJ, Kang HJ, Shin HY, Ahn HS (2007) Expression of Livin, an antiapoptotic protein, is an independent favorable prognostic factor in childhood acute lymphoblastic leukemia. Blood 109(2):471-477. https://doi.org/10.1182/ blood-2006-07-032557

23. Chomczynski P (1993) A reagent for the single-step simultaneous isolation of RNA, DNA and proteins from cell and tissue samples. BioTechniques 15(532-534):536-537

24. McPherson MJ (2000) The basic of PCR. New York BIOS Scientific publisher Limited, DOl: https://doi.org/10.1201/9780429258398.

25. Prat J, Mutch DG (2018) Pathology of cancers of the female genital tract including molecular pathology. Int J Gynecol Obstet 143:93-108. https://doi. org/10.1002/ijgo.12617

26. Attallah AM, El-Far M, Abdel Malak CA, Farid K, Omran MM, Yahya RS, Saad EA, Albannan MS, Attallah AA, El Basuni MA, Ali IS, Abed SB, El Naggar MA (2015) A simple diagnostic index comprising epithelial membrane antigen and fibronectin for hepatocellular carcinoma. Ann Hepatol 14(6):869-880. https://doi.org/10.5604/16652681.1171774

27. El-Emshaty HM, Saad EA, Gouida MS, Elshahawy ZR (2018) Associations between CD133, CK19 and G2/M in cirrhotic HCV (genotype-4) patients with or without accompanying tumor. Biocell 42(2):55-60. https://doi.org/1 0.32604/biocell.2018.07009 
28. Saad EA, Habib SA, Eltabeey MS (2017) Diagnostic performance of AFP, autotoxin and collagen IV and their combinations for non-invasive assessment of hepatic fibrosis staging in liver fibrosis patients associated with chronic HCV. IJPQA 8(04):165-173. https://doi.org/10.25258/ijpqa. v8i04.10542

29. Wong RS (2011) Apoptosis in cancer: from pathogenesis to treatment. J Exp Clin Cancer Res 30:87. https://doi.org/https://doi.org/10.1186/1756-9966-30$87,1$.

30. Faruk M, Ibrahim S, Aminu SM, Adamu A, Abdullahi A, Suleiman AM, Rafindadi AH, Mohammed A, lliyasu Y, Idoko J, Saidu R, Randawa AJ, Musa HS, Ntekim A, Shah KZ, Abubakar S, Adoke KU, Manko M, Awasum CA (2021) Prognostic significance of BIRC7/Livin, BCl-2, p53, Annexin V, PD-L1, DARC, MSH2 and PMS2 in colorectal cancer treated with FOLFOX chemotherapy with or without aspirin. PLoS One 16(1):e0245581

31. Zhuang L, Shen LD, Li K, Yang RX, Zhang QY, Chen Y, Gao CL, Dong C, Bi Q Tao JN, Wang XN, Tian Q (2015) Inhibition of livin expression suppresses cell proliferation and enhances chemosensitivity to cisplatin in human lung adenocarcinoma cells. Mol Med Rep 12(1):547-552. https://doi.org/10.3892/ mmr.2015.3372

32. Kasof GM, Gomes BC (2001) Livin, a novel inhibitor of apoptosis protein family member. J Biol Chem 276(5):3238-3246. https://doi.org/10.1074/jbc. M003670200

33. Dumétier B, Zadoroznyj A, Dubrez L (2020) IAP-mediated protein ubiquitination in regulating cell signaling. Cells 9 . https://doi.org/https://doi. org/10.3390/cells9051118, 9, 5.

34. Ye L, Song X, Li S, Yang D, Zhang J, Che X, Chen X, Wang J, Zhang Z (2011) Livin-a promotes cell proliferation by regulating G1-S cell cycle transition in prostate cancer. Prostate 71(1):42-51. https://doi.org/10.1002/pros.21220

35. Aggarwal V, Tuli HS, Varol A, Thakral F, Yerer MB, Sak K, Varol M, Jain A, Khan MA, Sethi G (2019) Role of reactive oxygen species in cancer progression: Molecular mechanisms and recent advancements. Biomolecules 9(11):735

36. Li N, Karin M (1999) Is NF-kappaB the sensor of oxidative stress? Faseb J 13(10):1137-1143. https://doi.org/10.1096/fasebj.13.10.1137

37. Ota H, Igarashi S, Sato N, Tanaka H, Tanaka T (2002) Involvement of catalase in the endometrium of patients with endometriosis and adenomyosis. Fertil Steril 78(4):804-809. https://doi.org/10.1016/S0015-0282(02)03344-7

38. Pejić S, Todorović A, Stojiljković V, Kasapović J, Pajović SB (2009) Antioxidant enzymes and lipid peroxidation in endometrium of patients with polyps, myoma, hyperplasia and adenocarcinoma. Reprod Biol Endocrinol 7:149

39. Saad EA, Elsayed SA, Hassanien MM, Al-Adl MS (2020) The new iron(III) 3oxo-N-(pyridin-2-yl)butanamide complex promotes Ehrlich solid tumor regression in mice via induction of apoptosis. Appl Organomet Chem 34(1): e5282. https://doi.org/10.1002/aoc.5282

\section{Publisher's Note}

Springer Nature remains neutral with regard to jurisdictional claims in published maps and institutional affiliations.

\section{Submit your manuscript to a SpringerOpen ${ }^{\circ}$ journal and benefit from:}

- Convenient online submission

- Rigorous peer review

- Open access: articles freely available online

- High visibility within the field

- Retaining the copyright to your article

Submit your next manuscript at $\boldsymbol{\nabla}$ springeropen.com 